\title{
ПРОФИЛАКТИЧЕСКАЯ ДЕЯТЕЛЬНОСТЬ пОЛИЦиИ
}

Куракин А.В., Костенников М.В., Мышляев Н.П.

\section{ПРАВОВОЕ РЕГУЛИРОВАНИЕ ДЕЯТЕЛЬНОСТИ ПОЛИЦИИ ПО ПРОФИЛАКТИКИ ПРАВОНАРУШЕНИЙ В ЗАРУБЕЖНЫХ ГОСУДАРСТВАХ}

Статья подготовлена при информационной поддержке компании «Консультант плюс»

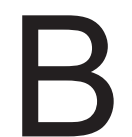

развитых государствах мира обеспечение публичной безопасности (в широком смысле) путем охраны правопорядка в общественных местах, контроля за соблюдением законов, постановлений и распоряжений органов власти (центральных и местных), оказания помощи отдельным гражданам, когда их жизни, здоровью, имуществу угрожает опасность или нарушаются их гражданские права, а также населению в целом при чрезвычайных обстоятельствах является одной из главных задач полиции и патрульной службы в частности, поскольку последняя в силу своей многофункциональности и универсальности является основной в полицейской системе [1]. Об этом можно судить по тому, что она поглощает 60-75 \% личного состава. Признанные специалисты по вопросам полицейской организации считают ее «становым хребтом всей полицейской системы» [2]. «Эффрективная патрульная служба - по мнению В. Леонарда и Г. Мора - является краеугольным камнем полицейской организации. Отдельно взятый патрульный - это первая линия обороны общества против преступника».

Отечественные специалисты, занимающиеся исследованием проблемы организации полиции зарубежных государств указывают что при всех имею- щихся различиях в ее организации наблюдается значительное сходство, а в ряде случаев идентичность элементов организации и деятельности патрульной службы развитых зарубежных стран (США, Великобритания, Франция, Канада, Германия, Япония).

Анализ научных источников показывает, что при определенных особенностях, присущих патрульной службе этих государств, основной акцент, по нашему мнению, необходимо сделать на изучении организации и деятельности патрульной службы США, воплотившей наиболее характерные ее черты. Это связано еще и с тем, что в США практикуются наиболее приемлемые формы и методы несения патрульной службы, выбор необходимых видов нарядов для ее организации в городах и других населенных пунктах.

Насколько важна роль, отводимая патрульной службе в системе американской полиции, можно судить по высказываниям авторов, посвятивших свои исследования ее деятельности. По их мнению, все остальные службы полиции носят вспомогательный характер по отношению к патрульной службе и существуют, поскольку этой службе в ряде случаев требуется специализированная помощь. 
Если классифицировать задачи патрульных полицейских, несущих службу в общественных местах, то в наибольшей степени они выполняют следующие основные задачи по:

- предупреждению преступлений и других правонарушений;

- расследованию преступлений и других правонарушений;

- поддержанию общественного порядка.

Кроме того, в круг их обязанностей входит выполнение целого комплекса функций: проведение профилактических мероприятий, устранение нарушений порядка, пресечение преступлений, регулировка и контроль дорожного движения, участие в розыске скрывшихся преступников, сбор информации, необходимой для других отраслевых служб, оказание помощи гражданам в экстренных ситуациях, не связанных с правонарушениями. В этой связи особо следует отметить и тот фракт, что функции патрульных нарядов не ограничиваются охраной порядка лишь на улицах и в других общественных местах, а распространяются и на жилой сектор[3].

Широте диапазона обязанностей полицейских в полной мере соответствует такой же широкий диапазон прав. Так, они вправе выносить официальное предупреждение о недопустимости дальнейшего противоправного поведения, накладывать штраф, задерживать правонарушителей, производить обыски, применять физические меры воздействия, использовать резиновые палки, наручники, огнестрельное оружие, гранаты со слезоточивым газом и др.

В структуре полицейских аппаратов, осуществляющих патрульную службу, выполнение всего перечня задач и функций возложено на ее низовые звенья - полицейские станции, отделения, участки, которые содержатся за счет местного бюджета.

В этой связи следует отметить, что в большинстве зарубежных стран общее руководство патрульной службой в региональном и национальном масштабе отсутствует. Управление ее обычно осуществляется на среднем (функциональном) уровне управления территориальным полицейским формированием. Например, в США, Англии, Германии высшей инстанцией оперативного руководства патрульной службой является полицейское управление города (района). Правда в некоторых странах определенная его доля осуществляется национальными центрами. При этом не имеется в виду повседневное оперативное руководство, речь идет лишь о некоторых, наиболее принципиальных проблемах.

Основными направлениями повышения эффрективности патрульной службы является совершенствование оперативного управления патрульной службой, призванного сократить время реагирования полиции на сообщения о правонарушениях за счет:

а) улучшения обслуживания вызовов;

б) более рационального использования рабочего времени, затрачиваемого на превентивное патрулирование.

Затрата времени на обработку поступающей информации в центрах руководства патрульной службой составляет для срочных дел в среднем 1,5 минуты, а не срочных 6 минут. Среднее время следование патруля на место происшествия колеблется от 2,5 до 3 минут после получения из диспетчерского пункта подразделения сообщения о преступлении или правонарушении.

Необходимость постоянного повышения результативности работы патрульных нарядов привела в ряде европейских стран и США к активизации процесса централизации управления всеми патрульными нарядами, действующими на территории города в специально создаваемых, для этой цели, оперативных отделах («мозговых центрах»). 
Особенность ситуации в том, что в организационном отношении патрульные силы остались по-прежнему рассредоточены по местным полицейским участкам (станциям, отделениям) и в их подчинении, а в оперативном отношении в период несения службы каждый патрульный наряд поступает в распоряжение единого центра.

Именно в центре осуществляется планирование, организация исполнения и контроль принятых решений, кадровое и материально-техническое обеспечение подразделения. Кроме того, было создано промежуточное управленческое звено, которым стали мобильные командные пункты, дислоцирующиеся на автомашинах, оборудованных необходимой техникой, радио и телефонной связью, другой аппаратурой.

Важнейшей практической задачей руководства патрульной службой является рациональное распределение имеющихся сил и средств. Рекомендуемая в настоящее время в США система предусматривает распределение работы не равномерно по сменам, а «пропорционально потребностям». При этом, во-первых, силы и средства патрульной службы должны распределятся в соответствии с изменениями оперативной обстановки, во-вторых, патрульные подразделения должны иметь приблизительно одинаковую нагрузку.

Проблема повышения эффективности патрульной службы обычно рассматривается в следующих, тесно связанных между собой аспектах: какой вид патруля наиболее эфрфективен, какое число патрульных (патрульных нарядов) необходимо для осуществления основных функций полиции на данной территории, какой техникой должен быть оснащен патруль и, наконец, какие формы управления патрулями дают оптимальный результат.
Расстановка патрулей и установление маршрутов их движения производится таким образом, чтобы у населения создалось впечатление о вездесущности полиции. Правонарушителей стараются заставить почувствовать, что они лишены возможности безнаказанно совершать правонарушения в связи с постоянным ее присутствием [4].

Необходимо отметить, что важным элементом в организации патрульной службы является правильный выбор нарядов патрулирования. Патрульная служба полиции использует различные виды нарядов. Выбор того или иного вида патрульных нарядов зависит от целого ряда фракторов: численности личного состава патрульной службы и обслуживаемого полицейским фрормированием населения; площади и топографии обслуживаемой территории, а также плотности населения в том или ином районе обслуживаемой территории; оперативной обстановки. Большое значение имеют время года и часы суток, климатические условия [5].

Патрульные наряды полиции в зарубежных странах можно подразделить в зависимости от численности на одиночный патруль, парный и групповой; в зависимости от способа передвижения - на пеший и моторизованный; в зависимости от характера решаемых задач - на общий и специальный.

Кроме того, в полициях большинства стран в классификации нарядов имеет значение пол полицейских. Существуют женские патрули, составляющие в некоторых регионах особую «женскую полицию».

В США, как и в других развитых зарубежных странах, используются все виды патрульных нарядов в зависимости от численности личного состава (одиночный, парный, групповой, оперативный). А от способа передвижения - пеший, автомобильный, авиапатруль, а также 
патрули, использующие другие средства передвижения - лошадей, велосипеды. Однако в сфрере охраны публичного порядка более распространены одиночные и парные патрули. Имеют место и смешанные комбинации: одновременно пеший и автомобильный патруль, одиночный и парный автомобильный, автомобильный патруль и патруль на мотороллерах и т.п.

Важную роль в работе полиции играет пешее патрулирование, особенно на участках, наиболее населенных или с высоким уровнем преступности и деликтности, где можно наиболее эфффективно реализовать превентивную функцию патрулирования.

Основные вопросы, решаемые при выборе видов патруля - насколько увеличивается эфффективность патрулирования при использовании автомашины и как автомашина должна использоваться.

К преимуществам моторизованного патрулирования относят высокую мобильность нарядов, возможность размещения в автомашине средств связи, криминалистической техники и независимость патруля от погодных условий. Главным же недостатком признается ослабление контактов с населением, в результате чего меньше используется этот важный источник информации.

Оптимальным вариантом считается использование моторизованных патрулей с вменением им в обязанность часто оставлять автомашину для совершения пеших обходов. В итоге патрулирование на автомобилях применяется в меньшем объеме, чем раньше. На него затрачивается менее 50 \% рабочего времени.

В небольших городах ряда стран, в частности Франции, иногда для патрулирования используются мотороллеры, что в какой-то степени рассматривается как альтернатива пешему и автомобильному патрулированию. Небольшая скорость мотороллеров, возможность проезда в самых узких местах позволяют полицейскому более внимательно наблюдать за обстановкой на участке, он может всегда остановится в любом месте и совершить пеший обход.

Велосипеды для несения патрульной службы использовались а течение многих десятилетий. В настоящее время они продолжают достаточно широко использоваться в полициях некоторых стран Европы и особенно Азии.

Согласно принятой в патрульно-постовой полиции классификации патрулирование может осуществляться четырьмя способами:

1. По стабильному маршруту, разрабатываемому заранее. Преимущество: более полный охват участка, облегчается контроль. Недостаток: шаблонный характер, существуют не просматриваемые места, полицейские утрачивают чувство самостоятельности.

2. По случайному маршруту, который избирается самим полицейским. Отмечается высокая эффрективность патрулирования, но контроль затруднен.

3. По выделяемым на территории секторам, в которых полицейские патрулируют по избранным маршрутам. Эффективность патрулирования высокая, однако сорера охвата вниманием оказывается суженной.

4. По важным пунктам, через который обязательно должен проследовать патруль (соединение 1-го и 2-го). Наиболее рационален для густонаселенных городских районов.

Помимо патрулей, которые несут службу в полицейской форме и на полицейских автомашинах, иногда создаются группы, которые решают поставленные перед ними задачи конспиративно. Это, так называемые специальные патрули, которые комплектуются полицейскими, переодетыми в гражданскую одежду. При патрулировании используются наиболее распространенные в данной стра- 
не марки автомашин, замаскированные под автомашины частных владельцев или такси. Патрули действуют главным образом в темное время суток в районах, отличающихся наиболее высоким уровнем преступности.

Создаются также специализированные патрульные подразделения, которым предоставлена неограниченная инициатива и свобода в выборе тактических приемов, они используются только для предупреждения определенных видов преступлений и борьбы с ними. Они могут прибегать к маскировке при помощи одежды, грима и других средств в зависимости от поставленных задач [6].

В отличие от других стран в Японии основными организационными единицами патрульно-постовой службы являются полицейские будки и полицейские посты, патрульные моторизованные группы, подвижные и охранные полицейские будки, контрольные и командно-диспетчерские пункты. Обычные полицейские будки и посты, патрульные моторизованные группы по традиции относятся к основной системе, а подвижные и охранные будки, а также контрольные пункты рассматриваются как звенья вспомогательной или дополнительной системы. Личный состав будок и полицейских постов имеют участки обслуживания с постоянным населением, а личный состав патрульных моторизованных групп, подвижных и охранных будок, контрольных пунктов считаются не имеющих таковых [7].

Будки создаются в городах, посты - в сельской местности. Первые оборудуют только служебными помещениями, вторые - служебными и жилыми. В районах застройки многоэтажными жилыми зданиями европейского типа используются подвижные полицейские будки - специально оборудованные автобусы.

По мнению японских официальных лиц, несение патрульно-постовой служ- бы включает в себя как патрулирование вне будки или поста, так и охрану во время нахождения личного состава внутри будки (поста). В качестве основной ее формы признаны контакты при обходе; данный принцип означает требования рационального сочетания методов несения службы.

Принцип территориального обслуживания реализуется, в частности, в том, что каждый из полицейских, входящий в личный состав одной будки, отвечает за порученную ему часть общего участка. Тяготеют к этому принципу и моторизованные патрули. Отделение полиции, например, объединяет будки в своеобразные блоки и на каждый из них выделяет патрульную автомашин.

Весьма важным в деятельности патрульной службы признано расширение и углубление контактов с населением. При этом преследуется несколько целей: получение необходимой информации, частичная превенция правонарушений, а также укрепление авторитета полиции и доверия к ней со стороны граждан. Вступать в контакт рекомендуется при малейшей возможности и не только с законопослушными гражданами, но и с лицами, чье поведение, внешний вид вызывают подозрение. Считается, что даже кратковременная беседа способствует нарушению асоциальной установки.

Вступление в контакт должно быть ненавязчивым и не вызывать у собеседника ощущение принудительности. Особое значение придается располагающей манере разговора полицейского, умение выбирать тему и маскировать интересующие его вопросы.

В этой связи оправдано мнение о необходимости внедрения в деятельность полиции достижений педагогики, психологии, так как это сделает методику работы полиции научно обоснованной, расширит ее возможности для 
работы со всеми возрастными, профессиональными группами и социальными слоями населения.

Патрульная служба противостоит правонарушителю всеми методами, включая - насильственные. В какой-то степени патруль выполняет все полицейские функции: не только предупреждает и пресекает нарушения общественного порядка и преступления, но и закрепляет доказательства совершения правонарушения, устраняет нарушения дорожного движения, занимается общей и индивидуальной профрилактикой. Подчас многие из этих функций реализуются недостаточно квалифрицированно, но это восполняется тем, что патрульные вездесущи, они находятся ближе всего к населению.

Весьма высокая эффрективность патрульной службы в значительной степени объясняется, кроме вышеуказанного, еще и тем, что в ряде зарубежных стран все или абсолютное большинство вновь принимаемых на работу в полицию направляются в патрульную службу. И возможность перемещения на более высокую должность или в другую службу ставится в прямую зависимость от квалификации полицейского и качественного выполнения им функциональных обязанностей.

Методы и фрормы патрулирования, используемые патрульной службой полиции США, являются приемлемыми в определенной степени и для нашей страны (в элементах организации). Так, в ряде городов США с высоким уровнем преступности и деликтности активно используется практика организации деятельности патрульной службы по «бригадному методу». Наиболее сложные в оперативном отношении городские районы обслуживаются «бригадами» или «комбинированными патрульными группами»: 5-7 патрульных полицейских (по одному в патрульной машине), два пе- ших патрульных, детектив, находящийся в одной из машин, сотрудник службы борьбы с пороками, сотрудник патрульной службы для организации и поддержания связи с центром (из любой патрульной машины).

«Бригадный метод», нацеленный в первую очередь на расследование преступлений, в то же время способствует повышению эффективности общеполицейских мероприятий по предупреждению правонарушений и охране порядка. При этом высокая мобильность и результативность «бригад», во-первых, порождает страх у потенциальных правонарушителей и вытесняет их из данного района обслуживания и, во-вторых, эти фракторы повышают доверие населения к полиции, стимулируя граждан к активному сотрудничеству и помощи полиции.

Одним их преимуществ «бригадного метода» является активное стремление сотрудников патрульной службы совершенствовать свои профессиональные навыки, работая в тесном и непосредственном контакте с детективами.

Кроме названных «бригад» могут создаваться специальные отряды, состоящие из сотрудников патрульной службы и приглашенных специалистов из полицейских формирований других городов. Деятельность этих отрядов носит временный характер и, как правило, направлена на борьбу с определенными видами преступлений, например, с хищениями автотранспортных средств, квартирными кражами, грабежами, изнасилованиями. Привлекаемые из других органов и ведомств сотрудники являются специалистами в сфере предупреждения и пресечения именно конкретных видов преступлений.

По мнению американских исследователей, использование специальных отрядов позволяет в случае необходимости осуществлять в районе быструю концентрацию полицейских сил, которые 
подготовлены соответствующим образом и ориентированы на активный поиск и задержание преступников и правонарушителей.

В городах с высокой плотностью населения часто используется групповой патруль. Численность его обуславливается оперативной необходимостью (но не меньше трех человек). В него, наряду с сотрудниками патрульной службы, входят представители других полицейских служб, чаще всего агенты уголовной полиции (детективы). На месте происшествия сотрудники патрульной службы принимают меры к ликвидации нарушений общественного порядка, а детектив проводит предварительное расследование «по горячим следам».

В последние годы вместо направления нарядов патрульной службы по вызовам «некритического» характера, их обслуживание осуществляется иными категориями персонала полиции в рамках так называемого полицейского консультирования по телефону (беседа полицейских-психологов, сотрудников службы по работе с несовершеннолетними и т.д.).

В организации деятельности патрульной службы в настоящее время используется метод «расщепленного патрульного подразделения». Он начал применятся с середины 70-х годов $\mathrm{XX}$ в. В рамках этого метода наряды патрульной службы разделены на две группы: реагирования (обслуживающую только вызовы и происшествия) и превентивную.

Наряды патрульной службы, входящие в группу реагирования, закреплены за районами города с высоким уровнем преступности и деликтности и находятся при стационарных базах, имеющих постоянную связь с диспетчерской службой полицейского департамента.

Патрульные наряды превентивной группы осуществляют патрулирование на территории всего города без какой- либо определенной привязки к районам и патрульным участкам.

Обе группы находятся в оперативном подчинении у начальника патрульного подразделения, а руководство ими осуществляется из диспетчерской службы полицейского департамента. В условиях чрезвычайных обстоятельств группы объединяют свои усилия для выполнения общих задач.

Эта концепция организации патрульной службы считается среди американских специалистов эфффективной и перспективной, поскольку она позволяет создать такие условия, при которых вызовы на происшествия «получают быстрое и оперативное обслуживание», а патрулирование, нацеленное на предупреждение преступности и охрану порядка, представляет собой постоянный процесс, который не прерывается различными вызовами.

В настоящее время в патрульной службе активно применяется прием «тактического опроса» с остановкой граждан и выяснения у них причин нахождения в данном районе. В целях выявления и уточнения места нахождения подозрительных лиц и разыскиваемых преступников «опрос» используется и в качестве составной части «насыщенного» патрулирования. Причем в комплексе все эти приемы рассматриваются специалистами как активная наступательная тактика, профилактика деликтности и борьба с преступностью средствами патрульной службы, создающая у потенциальных правонарушителей впечатление, что их действия могут попасть в поле зрения полиции.

Одной из разновидностей этого приема является «ориентированный опрос», при котором отдельные сотрудники или наряды патрульной службы нацелены на опросы определенной категории лиц (молодежь и подростки, алкоголики, наркоманы). 
Широко распространен тактический прием поиска и задержания правонарушителей с помощью «патруля, ориентированного на задержание». По своей сути это аналог действиям полицейской разведки при проведении наружного наблюдения. Различают действия такого патруля, наблюдающего за определенным объектом (дом, магазин и т.д.), или же осуществляющего наружное наблюдение за потенциальными преступниками и нарушителями порядка с тем, чтобы провести задержание во время совершения правонарушения.

Тактический прием - «поиск подозреваемого» - используется в целях активного поиска и задержания преступников и других правонарушителей «по горячим следам». На месте происшествия действует патрульный наряд, занимающийся расследованием, а свободные наряды соседних участков осуществляют объезд прилегающих районов, проводя опрос граждан, подозрительных лиц, досматривают машина и т.д.

Следует отметить, что использование подразделениями патрульной службы целенаправленных тактических приемов, широкое участие в мероприятиях по активному поиску и задержанию преступников потребовали не только повышения профессиональной подготовки сотрудников, но и вызвали необходимость создания в рамках подразделений патрульной службы специальных тактических групп, ориентированных на особые приемы и методы работы. В частности, рекомендовалось в подразделениях полиции, насчитывающих более 75 сотрудников, создание гибкого и мобильного тактического подразделения. Специальная тактика, по мнению зарубежных специалистов, должна применяться в том случае, если обычные традиционные формы патрулирования являются неэффективными.
В настоящее время практически во всех крупных городах США фрункционируют специальные тактические группы, которые входят в состав патрульно-постовой службы и подчиняются ее начальнику.

Настойчивое совершенствование тактических приемов и методов деятельности патрульно-постовой службы отражает попытки полиции усилить сдерживающее воздействие на постоянный рост преступности и деликтности (в значительной степени - уличной). Поэтому, как можно заметить, тенденцией развития тактики патрульной службы является ориентация приемов и методов работы на активный поиск и задержание преступников и других правонарушителей, в том числе с использованием элементов оперативно-розыскной деятельности. Анализ литературных источников показывает, что самым трудным в управлении патрулями является их рациональное распределение, исходя из наличных сил. Американский специалист по полицейскому управлению О. Вильсон предлагает воспользоваться специальной методикой, суть которой заключается в том, что территория разбивается на участки приблизительно одинаковые по количеству совершаемых на них правонарушений. На каждом участке обозначаются объекты, заслуживающие внимания, а также места совершения правонарушений за длительный период времени, по крайней мере за год [8].

Зарубежными учеными-полицеистами в последнее время проводились также исследования, касающиеся определения опасностей, которые могут определенным образом влиять и на личную безопасность граждан. К числу основных исследователи относят: технологический риск (загрязнение окружающей среды, деятельность АЭС, фризическое покушение на личность и собственность (кражи со взломом, разбой на улицах, 
терроризм); социальные и медицинские аномалии наркомания, СПИД); наличие групп потенциальных возмутителей спокойствия (панки, иммигранты).

Анализируя культурные и социальные критерии, исследователи отмечают, что чем выше культурный уровень, социальная категория или уровень жизни, тем меньше чувство боязни и страха и наоборот, бедность и низкий уровень образования - залог боязни и страха.

В развитых зарубежных государствах устранение таких негативных последствий видится в совершенствовании политики предупреждения преступлений. Причем главное внимание должно уделяться мероприятиям, направленным на улучшение в местном масштабе условий жизни и недопущение, таким образом, пополнения преступной среды. Полиция при этом должна выполнять роль партнера, выступающего совместно с местными органами управления и общественными организациями .

По мнению зарубежных специалистов, успех предупреждения правонарушений во многом зависит от взаимодействия полиции с населением.

Этот вывод основан на мнении, что полиция одна не в состоянии обуздать преступность и обеспечить безопасность граждан. Предполагается, что усилия местных общин США как добровольного, так и организованного характера, направленные на контролирование противоправных действий и снижение чувства неуверенности и не безопасности, должны осуществляться параллельно с официальными мероприятиями с тем, чтобы, несмотря на финансовые затруднения и без ущемления гражданских свобод, обеспечить безопасность населения.

Развивая тему предупреждения правонарушений, зарубежные авторы отмечают, что полиция, жандармерия и уголовная юстиция обязаны обеспечить выполнение социального заказа, выражаемого в форме жалоб и заявлений со стороны пострадавших. Поэтому любое заявление, касающееся даже незначительных правонарушений не должно оставаться нерассмотренным.

В некоторых государствах (например, Франция) МВД в качестве эксперимента проверяет эфрфективность практики заключения «контрактов безопасности» с добровольными организациями общин, смысл которых состоит в более рациональном распределении обязанностей между национальной и муниципальной полицией. Предполагается, что в результате этого национальная полиция могла бы, таким образом, освободиться от обязанностей, связанных с охраной остановок транспорта или дежурством около школ и т.п., и сосредоточиться на борьбе с преступностью.

В развитых зарубежных странах (США, Великобритания, Франция) зарекомендовала себя такая форма обеспечения безопасности, как квартальное наблюдение. Сотрудники полиции считают, что практика квартального наблюдения является также одной из эффрективных форм взаимодействия полиции и населения перед возможностью оказаться жертвой правонарушений. Реализация программы квартального наблюдения проводится по трем направлениям:

- объединение в группы граждан, проживающих в определенном районе, для ведения наблюдения за подозрительными лицами и информирования об этом полицию;

- маркировка имущества для оперативного обнаружения владельца похищенного имущества и розыска правонарушителей;

- организация посещений полицейскими домовладельцев и жителей района и оказание консультативной помощи по обеспечению безопасности квартир и частных домостроений. 
Первичные группы квартального наблюдения создаются либо по инициативе полиции, либо в результате ходатайства в полицию представителей местной общественности. Например, выбрав определенный район или квартал, сотрудники полиции налаживают контакт с местными общественными активистами, которые затем назначаются старшими групп.

Программа квартального наблюдения считается введенной в действие, если она утверждена на общем собрании жителей района или квартала, а из числа общественности выбран руководитель, который должен поддерживать непосредственный контакт с местными органами полиции.

По данным полицейской статистики, в местах действия квартального наблюдения отмечается снижение количества зарегистрированных преступлений и других правонарушений.

Между тем зарубежные специалисты предупреждают, что реализация квартального наблюдения может потерпеть крах как на начальной стадии (организации), так и в процессе его осуществления (функционирования). По их мнению, существуют две основные причины распада групп и объединений квартального наблюдения: сопротивление общественности и отсутствие поддержки со стороны полиции. Первая причина объясняется неверием населения в результативность внедрения в квартального наблюдения, порой формальным подходом полиции в ходе рекламы этого мероприятия и ее стремлением переложить свои заботы на плечи общественности. Вторая причина связана с постоянно существующими конфрликтами между сотрудниками полиции, занимающимися внедрением программы квартального наблюдения, с вышестоящими инстанциями, которые оценивают их работу по результатам, достигнутым в кротчайшее время (что не позволяет делать объективные выводы), а также непрестижностью подобной деятельности среди сотрудников полиции.

Таким образом, изучение вопросов, связанных с организацией и деятельностью полиции в ряде зарубежных стран, позволяет выявить устойчивые тенденции ее развития: наращивание численности личного состава; внедрение мобильных групп и использование их возможностей для усиления территориальных подразделений; закрепление за полицейскими определенных участков работы в целях повышения эфрфективности их деятельности и расширения контактов с населением; совершенствование системы подготовки кадров всех уровней; укрепление низовых органов обеспечения патрульной службы за счет концентрации сил и средств в меньшем, по сравнению с прежним, количеством полицейских станций; замена части моторизованных патрулей пешими; внедрение прогрессивных методов непосредственного несения службы.

\section{Библиография:}

1. Губанов А.В. Полиция Запада: основы деятельности по охране правопорядка. - М., 1993. - C.41.

2. Бристоу А. Эффрективное использование полицейских сил. Изд.4. Томас. Спрингфилд. Иллинойс. США, 1969. - С.78 // Сборник переводов. № 147. - М., ВНИИ МВД СССР, 1971. - С. 12.

3. Белоусов Н.М., Коновалов Д.Н., Крылов Б.С. Патрульно-постовая служба в полициях буржуазных стран. - М., 1984. - С. 17.

4. Вильсон О. Планирование работы полиции. Иллинойс. США. М., 1963. - С. 61. 


\section{Полицейская деятельность 1 • 2015}

5. Полиция и борьба с преступностью за рубежом (информационный сборник). - М., 1991. - С.76.

6. Губанов А.В. Полиция Запада: основы деятельности по охране правопорядка. - М., 1997. - C. 48.

7. Кин Уеда. Преступность и криминология в современной Японии. М., 1989. - С.149.

8. Вильсон О. Планирование работы в полиции. М., 1963. - С. 64.

9. Редкоус В.М. Административно-правовое регулирование противодействия коррупции на Украине // Административное и муниципальное право. - 2010. - 7. - С. 39 - 45.

10. Куракин А.В., Костенников М.В. Административно-правовое противодействие коррупции в системе государственной службы и в деятельности сотрудников полиции Российской Федерации и зарубежных государств // Полицейская и следственная деятельность. 2013. - 1. - C. 65 - 83. DOI: 10.7256/2409-7810.2013.1.735. URL: http://www.e-notabene.ru/ pm/article_735.html

\section{References (transliterated):}

1. Gubanov A.V. Politsiya Zapada: osnovy deyatel'nosti po okhrane pravoporyadka. - M., 1993. - S.41.

2. Bristou A. Effektivnoe ispol'zovanie politseiskikh sil. Izd.4. Tomas. Springfild. Illinois. SShA, 1969. - S.78 // Sbornik perevodov. № 147. - M., VNII MVD SSSR, 1971. - S. 12.

3. Belousov N.M., Konovalov D.N., Krylov B.S. Patrul'no-postovaya sluzhba v politsiyakh burzhuaznykh stran. - M., 1984. - S. 17.

4. Vil'son O. Planirovanie raboty politsii. Illinois. SShA. M., 1963. - S. 61.

5. Gubanov A.V. Politsiya Zapada: osnovy deyatel'nosti po okhrane pravoporyadka. - M., 1997. - S. 48.

6. Kin Ueda. Prestupnost' i kriminologiya v sovremennoi Yaponii. M., 1989. - S.149.

7. Vil'son O. Planirovanie raboty v politsii. M., 1963. - S. 64.

8. Redkous V.M. Administrativno-pravovoe regulirovanie protivodeistviya korruptsii na Ukraine // Administrativnoe i munitsipal'noe pravo. - 2010. - 7. - C. $39-45$.

9. Kurakin A.V., Kostennikov M.V. Administrativno-pravovoe protivodeistvie korruptsii v sisteme gosudarstvennoi sluzhby i v deyatel'nosti sotrudnikov politsii Rossiiskoi Federatsii i zarubezhnykh gosudarstv // Politseiskaya i sledstvennaya deyatel'nost'. - 2013. - 1. - C. 65 - 83. DOI: 10.7256/2409-7810.2013.1.735. URL: http://www.e-notabene.ru/pm/article_735.html 